\title{
Using a GIS to Assess the Land Movements Hazard: Application on Berhoum Area, Hodna Basin, Algeria
}

\author{
Amar Guettouche \\ Civil Engineering Department, Faculty of Technology, Ferhat Abbas University, Setif 1, Algeria \\ Email: guettouche.amar@gmail.com
}

How to cite this paper: Guettouche, A. (2019) Using a GIS to Assess the Land Movements Hazard: Application on Berhoum Area, Hodna Basin, Algeria. Journal of Geographic Information System, 11, 166-184.

https://doi.org/10.4236/jgis.2019.112012

Received: March 27, 2019

Accepted: April 13, 2019

Published: April 16, 2019

Copyright $\odot 2019$ by author(s) and Scientific Research Publishing Inc. This work is licensed under the Creative Commons Attribution International License (CC BY 4.0).

http://creativecommons.org/licenses/by/4.0/

\begin{abstract}
Modeling land movements hazard by multi-criteria approach is a line of research to provide a methodological framework for risk mapping. This work is intended to establish a model for mapping "land movements hazard" by GIS approach based on multi-criteria analysis. The methodology is to create thematic maps by combining in GIS, determining factors (slope, lithology, water, ...) in triggering landslides phenomena and shrinking-swelling soil, using the method of Weighted Sum Model (WSM). These maps are then combined to provide a hazard map of land movements. The application of this method allows the spatial distribution of different criteria and phenomena in Berhoum area, region of Hodna Basin, eastern Algeria. As a result, the study area has been divided into four different areas: 1) areas with no land movements hazard, 2) areas with a medium land movements hazard, 3) areas with a high land movements hazard, and 4) areas with very high land movements hazard.
\end{abstract}

\section{Keywords}

Land Movements, Hazard, MCDA, GIS, Berhoum

\section{Introduction}

Natural risks threaten with more or less intensity the human activities. Algeria has been frequently touched by natural disasters; these last ones put in danger life of persons and would make inestimable damages.

The north regions of Algeria, characterized by population density and speed of urban growth, are witnessing difficulties in construction caused by problems related to the land movements. This is due to the weakness of knowledge of phenomenon like: landslides and shrinking-swelling soil. 
Land movements include all field cases of land masses displacement under the action of gravity. They can be very slow or very fast.

Land movements can be classified into two types: Slope Movements: these are oblique movements, which affect both natural and artificial slopes, collapses, slides, ect., Vertical movements which include subsidence, collapses, settlements, ect., which result from the progressive consolidation of sediments under the influence of their own weight ... they can be caused either by local overload, the soil surface as that resulting of construction of a work, or by extraction of subsurface material, as in the exploitation of oil, water [1].

Based on this definition, the land movements are associated with two basic components: Landslides and shrinking-swelling soil. Landslides and shrinking-swelling soil constitute the largest classes of hazards.

The hazard assessment of land movements, including landslides and shrinking-swelling soil has been the subject of several research papers [2]-[11].

Several relationships and mathematical models hazard have been established, based on a single standard or several standards, and specialized in specific phenomenon, such as landslides or shrinking-swelling soil.

Is there any way to collect and evaluate these two phenomena together?

This can be achieved by integrating the Multicriteria Decision Analysis (MCDA) and the analytical capabilities of GIS [12].

There are several methods for solving and evaluating selection problems in MCDM [13] [14]. The main technique closely related to this paper is Weighted Sum Model (WSM). WSM can be described as a weighted linear combination or scoring method [15] [16]. WSM is a representation of the Decision Maker's preferences in a linear additive function [17]. Triantaphyllou and Mann [18] examined the effectiveness of decision-making methods and pointed WSM as one of the simplest methods for solving MCDM problems [19].

In general, suppose that a given MCDA problem is defined on $\mathrm{m}$ alternatives and $\mathrm{n}$ decision criteria, furthermore, let us assume that all the criteria are benefit criteria, that is, the higher the values are, the better it is. Next suppose that $w_{j}$ denotes the relative weight of importance of the criterion $C_{j}$ and $a_{i j}$ is the performance value of alternative $A_{i}$ when it is evaluated in terms of criterion $C_{j}$. Then, the total (i.e., when all the criteria are considered simultaneously) importance of alternative $A_{i}$, denoted as $A_{i}^{W S M-s c o r e}$, is defined as follows:

$$
A_{i}^{W S M-\text { score }}=\sum_{j=1}^{n} a_{i j} w_{j} \text {, for } n=1,2,3, \cdots, m
$$

For the maximization case, the best alternative is the one that yields the maximum total performance value [20].

From (1), the intuitive nature and ease of dealing with Multicriteria Decision-Making problems can be seen, and this simplicity makes WSM one of the most important methods for both exploring possible solutions for a Multicriteria Decision-Making problem and providing solutions in comparison to other methods [13]. 
This work aims to use a model of land movements hazard based on multicriteria analysis approach and assessment by GIS. This model, using (WSM) method in the framework of GIS is tested, and the obtained results have been discussed. The results provide useful information about landslides and shrinking-swelling risks mitigation and may serve as guidelines for land use planning in Berhoum area.

The study is part of the contribution to Berhoum area management, which is vulnerable to natural hazards, and also in the context of the production of information and awareness documents. So, the preventive methods remain the best way to overcome these problems or reduce them. One of the means that allows the adoption of effective preventive methods is to understand the phenomenon and predict the places it occurs in.

The choice of site of investigation is focused on Berhoum area, located in the South eastern of Algiers and is part of El Hodna Basin in north-east of Algeria (Figure 1). This choice is dictated by its diversity natural properties and density of equipment.

\section{Methodology}

After identification of the parameters involved in land movements, a mathematical model has been well established.

In order to obtain land movements hazard model of the study area the method of Weighted Sum Model (WSM) was applied (Figure 2).

In the analysis, weight values to the layers and rank values to the classes of each layer were assigned. For each class of the layer, rankings were given according to their significance. After the rankings were assigned to the classes of each layer, the weights were assigned to layers according to their importance. The interaction between the layers was not taken into consideration since the layers were assumed to be independent of each other [15] [16].

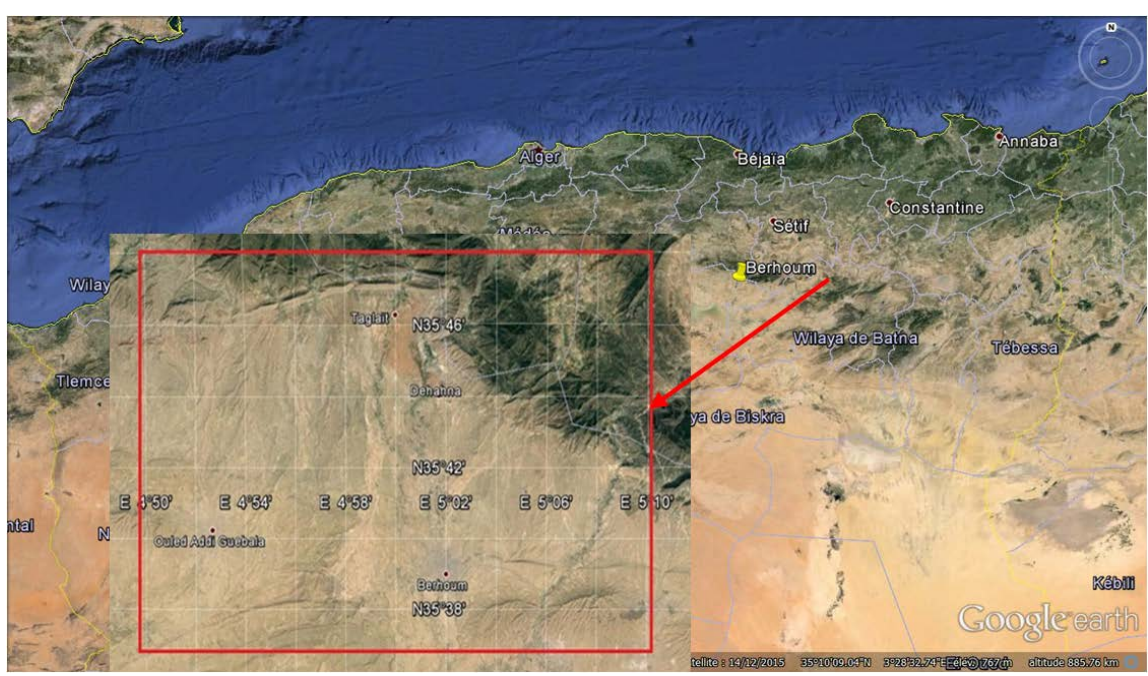

Figure 1. Location of Berhoum area (Source: Google Earth). 


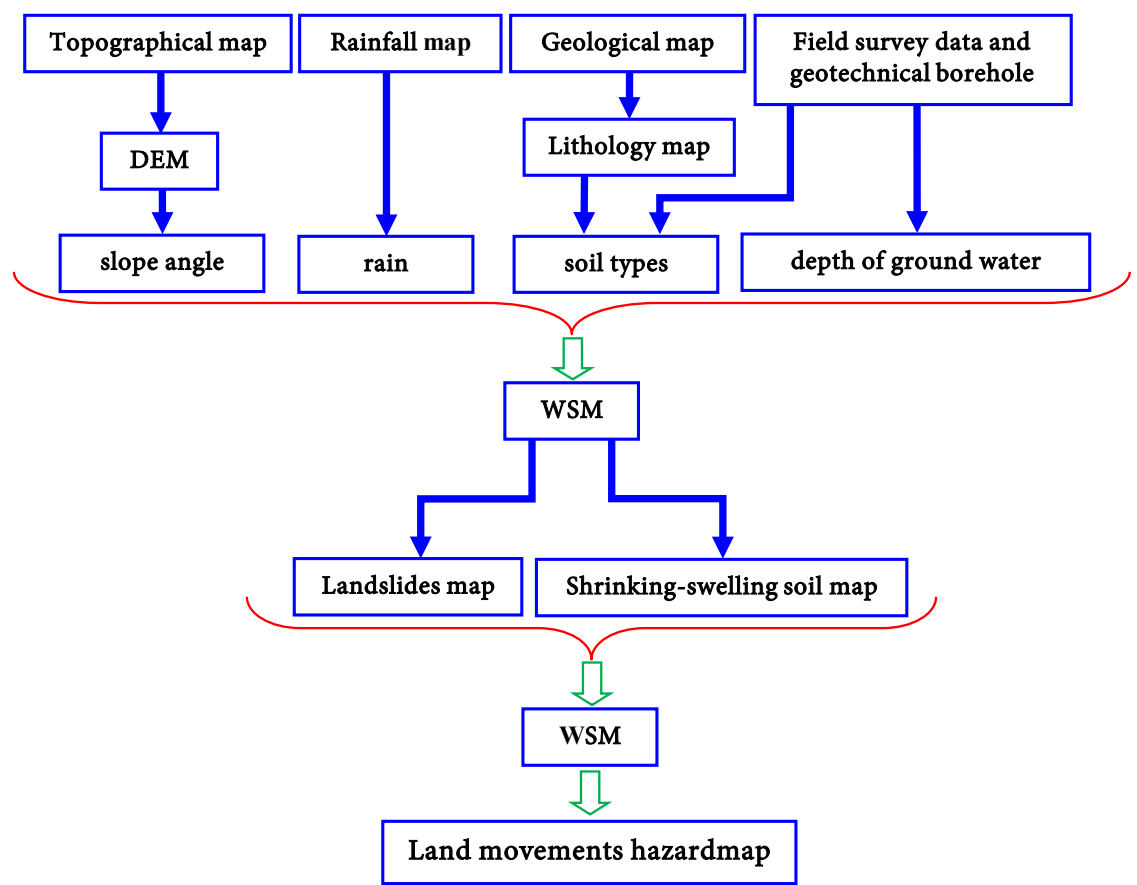

Figure 2. Organization chart of a Geographic Information System for Land movements hazard mapping.

The weights values, and classification in (WSM) model, are based on opinions of experts (Sounding views was conducted with a group of experts in the framework of the preparation of the doctoral thesis of the author scientific article) [21].

The weight and rank values of the layers and classes of each layer were standardized in order to obtain a common dimensionless unit. Afterwards, the output was created by multiplying the weight value assigned to each layer by the rank value given to the classes of that layer and finally by adding up the products [22].

We apply these steps to get the landslide map, as well as the shrinking-swelling soil map.As a result, the land movements hazard map of Berhoum area was grouped into different zones.

The application of the proposed model, suggested uses the SIG approach. We examine it as follows:

\subsection{Hypotheses}

To achieve this model, assumptions must be made. In this context, two hypotheses arise:

- The land movements are a phenomenon that can be evaluated by Landslides and shrinking-swelling soil, phenomena.

- Hazard is the weighted sum of these factors.

\subsection{Modelling Land Movements Hazard}

Land movements hazard is also the weighted sum (WSM) of the determinants of 
the phenomenon. Land movements hazard is given by the following relationship:

$$
H_{L M}=\sum_{1}^{n} w_{i} \cdot C_{i}
$$

where:

$W_{i}$ : weight assigned to each determinant, $C_{\dot{i}}$ : criteria.

According to the definition of land movement's hazard, it is the sum of landslide and shrinking-swelling soil. The combined effect of these two parameters is expressed by the following equation:

$$
H_{L M}=0.5 H_{L S}+0.5 H_{S S}
$$

where:

$H_{L M}$ : the land movements Hazard, $H_{L S}$ the landslides Hazard, $H_{S S}$ the shrinking-swelling soil Hazard.

\subsubsection{Modelling of the Landslide Hazard}

Based on the principle of the weighted sum, and in relation to the slope, water and soil, the landslide Hazard is given by the following formula:

$$
H_{L S}=0.4 P+0.4 T S+0.1 P N P+0.1 E P
$$

where:

P: slope angle, TS: soil types, PNP: depth of ground water table, EP: rain.

\subsubsection{Modelling of Shrinking-Swelling Soil Hazard}

On the same basis, and in relation to the types of soil and water, the shrinking-swelling soil hazard is given by the following formula:

$$
H_{S S}=0.6 T S+0.2 P N P+0.2 E P
$$

where:

TS: soil types, PNP: depth of ground water table, EP: rain.

\subsubsection{Criteria Used to Shrinking-Swelling Soil and Landslide Hazards}

Slope angle (P): Most large landslides related to the slope angles whose value generally exceeds $45 \%$. The slope angle values have been divided into four categories (Table 1).

Soil types (TS): Return to LPC classification, fine soils [Little plastic clay (Ap), Very plastic clay (At), Little plastic silt (Lp) and Very plastic silt (Lt)], are considered the most sensitive to swelling-shrinkage soil phenomena. The granular soils [Gravel (G) and Sand (S)] and the rocks are far from being affected by this phenomenon. Soil types were divided into four categories (Table 2).

The presence of groundwater and water content of soil variations due to seasonal climatic variations complicates swelling-shrinkage phenomena and landslides.

Depth of ground water table (PNP): The depth of groundwater table was divided into four categories (Table 3).

Rain (EP): The rain was divided into four categories (Table 4). 


\subsubsection{Crossing between the Parameters and Classification}

To make the crossing between the parameters, it is better to segment them into classes according to their degree of effect. The results are listed in Table $5 \& \mathrm{Ta}$ ble 6.

The combination of the weighted results of the different criteria, one by one and taking the common factors in each time, gives the level of each phenomenon, which we have presented in the form of tables.

Intersection matrixes for landslide are given as follows (Table 7).

Intersection matrixes for shrinking-swelling soil are given as follows (Table 8).

\subsubsection{Classification for Landslide and Shrinking-Swelling Soil Hazards}

The classification for landslides hazard is represented in Table 9.

The classification for shrinking-swelling soil is represented in Table 10.

\subsubsection{Modelling Land Movements Hazard}

For a combination of sliding and shrinking-swelling, formula (3) is applied for modeling the map of land movement's hazard. The rank of weights and values are follows in Table 11.

Intersection matrixes are given as follows tables (see Table 12 and Table 13).

Table 1. Classifications of slope effect on the hazard (P).

\begin{tabular}{ccc}
\hline Criteria & Grade & Classes \\
\hline$P<15^{\circ}$ & 1 & No effect \\
$15^{\circ} \leq P<30^{\circ}$ & 2 & Low to medium effect \\
$30^{\circ} \leq P<45^{\circ}$ & 3 & High effect \\
$P \geq 45^{\circ}$ & 4 & Very high effect \\
\hline
\end{tabular}

Table 2. Soil types effect on the hazard (TS).

\begin{tabular}{ccc}
\hline Criteria & Grade & Classes \\
\hline$R o c k / G / S$ & 1 & No effect \\
$L t / L p$ & 2 & Low to medium effect \\
$A p$ & 3 & High effect \\
$A t$ & 4 & Very high effect
\end{tabular}

Table 3. Classifications of depths of the groundwater table effect on the hazard (PNP).

\begin{tabular}{ccc}
\hline Criteria & Grade & Classes \\
\hline$P N P \geq 10 \mathrm{~m}$ & 1 & No effect \\
$5 m \leq P N P<10 \mathrm{~m}$ & 2 & Low to medium effect \\
$3 m \leq P N P<5 \mathrm{~m}$ & 3 & High effect \\
$P N P<3 m$ & 4 & Very high effect \\
\hline
\end{tabular}


Table 4. Classifications of rain effect on the Hazard (EP).

\begin{tabular}{ccc}
\hline Criteria & Grade & Classes \\
\hline$E P \leq 300 \mathrm{~mm} /$ year & 1 & No effect \\
$300 \mathrm{~mm} /$ year $<E P \leq 600 \mathrm{~mm} /$ year & 2 & Low to medium effect \\
$600 \mathrm{~mm} /$ year $<E P \leq 800 \mathrm{~mm} /$ year & 3 & High effect \\
$E P>800 \mathrm{~mm} /$ year & 4 & Very high effect \\
\hline
\end{tabular}

Table 5. Weights and values of the criteria for landslide Hazard.

\begin{tabular}{|c|c|c|c|}
\hline Criteria & Weights & Values & Classification \\
\hline \multirow{4}{*}{$P$} & \multirow{4}{*}{0.4} & 0.4 & No effect \\
\hline & & 0.8 & Low to medium effect \\
\hline & & 1.2 & High effect \\
\hline & & 1.6 & Very high effect \\
\hline \multirow{4}{*}{$T S$} & \multirow{4}{*}{0.4} & 0.4 & No effect \\
\hline & & 0.8 & Low to medium effect \\
\hline & & 1.2 & High effect \\
\hline & & 1.6 & Very high effect \\
\hline \multirow{4}{*}{$P N P$} & \multirow{4}{*}{0.1} & 0.1 & No effect \\
\hline & & 0.2 & Low to medium effect \\
\hline & & 0.3 & High effect \\
\hline & & 0.4 & Very high effect \\
\hline \multirow{4}{*}{$E P$} & \multirow{4}{*}{0.1} & 0.1 & No effect \\
\hline & & 0.2 & Low to medium effect \\
\hline & & 0.3 & High effect \\
\hline & & 0.4 & Very high effect \\
\hline
\end{tabular}

Values $=$ grades $\times$ weight.

Table 6. Weights and values of the criteria for shrinking-swelling soil Hazard.

\begin{tabular}{cccc}
\hline Criteria & Weights & Values & Classification \\
\hline \multirow{2}{*}{$T S$} & 0.6 & No effect \\
& & 1.2 & Low to medium effect \\
& 1.8 & High effect \\
& 2.4 & Very high effect \\
& 0.2 & No effect \\
& 0.2 & 0.4 & Low to medium effect \\
& & 0.6 & High effect \\
& & 0.8 & Very high effect \\
& & 0.2 & No effect \\
& & 0.4 & Low to medium effect \\
& & 0.6 & High effect \\
& 0.2 & 0.8 & Very high effect
\end{tabular}

Values $=$ grades $\times$ weight 
Table 7. (a) Matrix combination $(\mathrm{P}+\mathrm{TS}=\mathrm{C} 1)$; (b) Matrix combination $(\mathrm{C} 1+\mathrm{PNP}=$ $\mathrm{C} 2)$; (c) Matrix for landslide (C2 + EP).

(a)

\begin{tabular}{ccccc}
\hline $\mathbf{P}$ & $\mathbf{0 . 4}$ & $\mathbf{0 . 8}$ & $\mathbf{1 . 2}$ & $\mathbf{1 . 6}$ \\
\hline $\mathbf{T S}$ & 0.8 & 1.2 & 1.6 & 2.0 \\
$\mathbf{0 . 4}$ & 1.2 & 1.6 & 2.0 & 2.4 \\
$\mathbf{1 . 2}$ & 1.6 & 2.0 & 2.4 & 2.8 \\
$\mathbf{1 . 6}$ & 2.0 & 2.4 & 2.8 & 3.2 \\
\hline
\end{tabular}

(b)

\begin{tabular}{cccccccc}
\hline C1 & & & & & & \\
PNP & 0.8 & 1.2 & 1.6 & 2.0 & 2.4 & 2.8 & 3.2 \\
0.1 & 0.9 & 1.3 & 1.7 & 2.1 & 2.5 & 2.9 & 3.3 \\
0.2 & 1.0 & 1.4 & 1.8 & 2.2 & 2.6 & 3.0 & 3.4 \\
0.3 & 1.1 & 1.5 & 1.9 & 2.3 & 2.7 & 3.1 & 3.5 \\
0.4 & 1.2 & 1.6 & 2.0 & 2.4 & 2.8 & 3.2 & 3.6 \\
\hline
\end{tabular}

(c)

\begin{tabular}{llllllllllllllll}
\hline C2 & EP & 0.9 & 1.0 & 1.1 & 1.2 & 1.3 & 1.4 & 1.5 & 1.6 & 1.7 & 1.8 & 1.9 & 2.0 & 2.1 & 2.2 \\
\hline $\mathbf{0 . 1}$ & 1.0 & 1.1 & 1.2 & 1.3 & 1.4 & 1.5 & 1.6 & 1.7 & 1.8 & 1.9 & 2.0 & 2.1 & 2.2 & 2.3 \\
$\mathbf{0 . 2}$ & 1.1 & 1.2 & 1.3 & 1.4 & 1.5 & 1.6 & 1.7 & 1.8 & 1.9 & 2.0 & 2.1 & 2.2 & 2.3 & 2.4 \\
$\mathbf{0 . 3}$ & 1.2 & 1.3 & 1.4 & 1.5 & 1.6 & 1.7 & 1.8 & 1.9 & 2.0 & 2.1 & 2.2 & 2.3 & 2.4 & 2.5 \\
$\mathbf{0 . 4}$ & 1.3 & 1.4 & 1.5 & 1.6 & 1.7 & 1.8 & 1.9 & 2.0 & 2.1 & 2.2 & 2.3 & 2.4 & 2.5 & 2.6 \\
C2 & & & & & & & & & & & & & & \\
EP & 2.3 & 2.4 & 2.5 & 2.6 & 2.7 & 2.8 & 2.9 & 3.0 & 3.1 & 3.2 & 3.3 & 3.4 & 3.5 & 3.6 \\
$\mathbf{0 . 1}$ & 2.4 & 2.5 & 2.6 & 2.7 & 2.8 & 2.9 & 3.0 & 3.1 & 3.2 & 3.3 & 3.4 & 3.5 & 3.6 & 3.7 \\
$\mathbf{0 . 2}$ & 2.5 & 2.6 & 2.7 & 2.8 & 2.9 & 3.0 & 3.1 & 3.2 & 3.3 & 3.4 & 3.5 & 3.6 & 3.7 & 3.8 \\
$\mathbf{0 . 3}$ & 2.6 & 2.7 & 2.8 & 2.9 & 3.0 & 3.1 & 3.2 & 3.3 & 3.4 & 3.5 & 3.6 & 3.7 & 3.8 & 3.9 \\
$\mathbf{0 . 4}$ & 2.7 & 2.8 & 2.9 & 3.0 & 3.1 & 3.2 & 3.3 & 3.4 & 3.5 & 3.6 & 3.7 & 3.8 & 3.9 & 4.0 \\
\hline
\end{tabular}

Table 8. (a) Matrix combination (TS + PNP = C1); (b) Matrix for shrinking-swelling soil $(\mathrm{C} 1+\mathrm{EP})$.

(a)

\begin{tabular}{ccccc}
\hline TS & 0.6 & 1.2 & 1.8 & 2.4 \\
PNP & 0.8 & 1.4 & 2.0 & 2.6 \\
0.2 & 1.0 & 1.6 & 2.2 & 2.8 \\
0.4 & 1.2 & 1.8 & 2.4 & 3.0 \\
0.6 & 1.4 & 2.0 & 2.6 & 3.2 \\
0.8 & & & \\
\hline
\end{tabular}


(b)

\begin{tabular}{llllllllllllll}
\hline C1 & $\mathbf{0 . 8}$ & $\mathbf{1 . 0}$ & $\mathbf{1 . 2}$ & $\mathbf{1 . 4}$ & $\mathbf{1 . 6}$ & $\mathbf{1 . 8}$ & $\mathbf{2 . 0}$ & $\mathbf{2 . 2}$ & $\mathbf{2 . 4}$ & $\mathbf{2 . 6}$ & $\mathbf{2 . 8}$ & $\mathbf{3 . 0}$ & $\mathbf{3 . 2}$ \\
$\mathrm{EP}$ & & & & & & & & & & & & & \\
\hline $\mathbf{0 . 2}$ & 1.0 & 1.2 & 1.4 & 1.6 & 1.8 & 2.0 & 2.2 & 2.4 & 2.6 & 2.8 & 3.0 & 3.2 & 3.4 \\
$\mathbf{0 . 4}$ & 1.2 & 1.4 & 1.6 & 1.8 & 2.0 & 2.2 & 2.4 & 2.6 & 2.8 & 3.0 & 3.2 & 3.4 & 3.6 \\
$\mathbf{0 . 6}$ & 1.4 & 1.6 & 1.8 & 2.0 & 2.2 & 2.4 & 2.6 & 2.8 & 3.0 & 3.2 & 3.4 & 3.6 & 3.8 \\
$\mathbf{0 . 8}$ & 1.6 & 1.8 & 2.0 & 2.2 & 2.4 & 2.6 & 2.8 & 3.0 & 3.2 & 3.4 & 3.6 & 3.8 & 4.0 \\
\hline
\end{tabular}

Table 9. Landslide hazard classification.

\begin{tabular}{ccc}
\hline & Classes & Hazard Level \\
\hline$H_{L S} \leq 2$ & 1 & No hazard \\
$2<H_{L S} \leq 3$ & 2 & Low to medium hazard \\
$3<H_{L S} \leq 3.5$ & 3 & High hazard \\
$H_{L S}>3.5$ & 4 & Very high hazard \\
\hline
\end{tabular}

Table 10. Shrinking-swelling soil hazard classification.

\begin{tabular}{ccc}
\hline & Classes & Hazard Level \\
\hline$H_{S S} \leq 2$ & 1 & No hazard \\
$2<H_{S S} \leq 3$ & 2 & Low to medium hazard \\
$3<H_{S S} \leq 3.5$ & 3 & High hazard \\
$H_{S S}>3.5$ & 4 & Very high hazard \\
\hline
\end{tabular}

Table 11. Weights and values of the criteria.

\begin{tabular}{cccc}
\hline Criteria & Weights & Values & Hazard Level \\
\hline & & 0.5 & No hazard \\
$H_{L S}$ & 0.5 & 1.0 & Low to medium hazard \\
& 1.5 & High hazard \\
& 2.0 & Very high hazard \\
& 0.5 & No hazard \\
\multirow{2}{*}{$H_{S S}$} & 1.0 & Low to medium hazard \\
& & 1.5 & High hazard \\
& 2.0 & Very high hazard \\
\hline
\end{tabular}

Values $=$ grades $\times$ weight.

Table 12. Matrix combination $\left(\mathrm{H}_{\mathrm{LS}}+\mathrm{H}_{\mathrm{SS}}\right)$.

\begin{tabular}{lllll}
\hline $\mathrm{H}_{\mathrm{LS}}$ & 0.5 & 1.0 & 1.5 & 2.0 \\
$\mathrm{H}_{\text {SS }}$ & 1.0 & 1.5 & 2.0 & 2.5 \\
\hline 0.5 & 1.5 & 2.0 & 2.5 & 3.0 \\
1.0 & 2.0 & 2.5 & 3.0 & 3.5 \\
1.5 & 2.5 & 3.0 & 3.5 & 4.0 \\
\hline 2.0 & &
\end{tabular}

Colors reflect the degree of land movements Hazard $\left(\mathrm{H}_{\mathrm{LM}}\right)$. 
Table 13. Land movements hazard classifications.

\begin{tabular}{ccc}
\hline & classes & Hazard Level \\
\hline$H_{L M} \leq 1.5$ & 1 & No hazard \\
$1.5<H_{L M} \leq 2.5$ & 2 & Low to medium hazard \\
$2.5<H_{L M} \leq 3.5$ & 3 & High hazard \\
$H_{L M}>3.5$ & 4 & Very high hazard \\
\hline
\end{tabular}

\section{Spatialization by GIS Approach: Application in the Berhoum Area}

The approach we have adopted for the spatial distribution map preparation to assess the land movements Hazard is based on the geographic information systems.

The data sets used in this study can be grouped in four main data sources as lithological map (rocks' map), field survey and geotechnical drilling data, topographical map and rainfall map. These data obtained from the topographical map, rainfall map, lithology map or from the field survey and geotechnical drilling, have been implemented in GIS program (Arc Gis 9.3) for the primary maps drawing.

After the building of a database of the geographic reference, organizing and structuring it by the use of programs, a map of the land movements Hazard that shows the best areas for building.

\subsection{Data Sources}

\subsubsection{Lithology Map}

The lithology map is derived from the geological map of the study area [23]. After numeration of the geological map, the rocky facets' database has building. For the study area, nine lithological units were identified (Figure 3). These units include Dolomite, Limestone, Sandstone, Conglomerate, Marls, Clays, Coarse Alluvium Sandy-Clay Alluvium and Fine Alluvium. In the study area, Dolomite, Limestone, Sandstone, and Conglomerate Formations were classified as rock.

\subsubsection{Field Survey Data and Geotechnical Borehole}

Indeed, three techniques-different but complementary, have been used to complete the database:

- The relevant data of 49 study geotechnical surveys were reviewed and evaluated,

- Well field investigation based on direct observations,

- As well as recordings and field sampling (GPS, images, etc.).

Soil types (TS) and the groundwater table layers are prepared using lithology map and geotechnical borehole (Figure 4 and Figure 5).

\subsubsection{The Topographical Map}

The topographical map in scale $1 / 50,000$ is used to obtain the Digital Elevation Model (DEM) of the study area. The latter was obtained by digitizing the contour lines of the topographical map. It is the software Arc Gis 9.3 which was used for the interpolation. The slopes map is prepared by degrees, using the DEM of the study area (Figure 6). 


\subsubsection{The Rainfall Map}

The rainfall map in scale $1 / 50.000$ is used to obtain the rain water layer of Berhoum area (Figure 7).

\subsection{Data Evaluation}

These data were consolidated and evaluated to obtain landslide and shrinking-swelling soil hazards maps (Figure 8 and Figure 9). To implement these steps, we use the machine tool calculator networking (Calculator Raster) of spatial analysis toolbar (Suitability Special) in Arc Gis 9.3 [24].

\subsection{Identification and Classification of Land Movement's Hazard}

Combining the results of landslides and shrinking-swelling soil (Formula 3), gives the degree of movements Hazard $\left(\mathrm{H}_{\mathrm{LM}}\right)$, we have presented in the form of Figure 10.

\section{Validation of Land Movements Hazard Map}

Validation of the results was done at two levels. On the one hand, the thematic maps obtained were compared with the field data before their crossing. The perfect match between these field observations (Figure 11) and the medium and high hazard sites revealed by the map made from the GIS allows validating to some extent the final map.

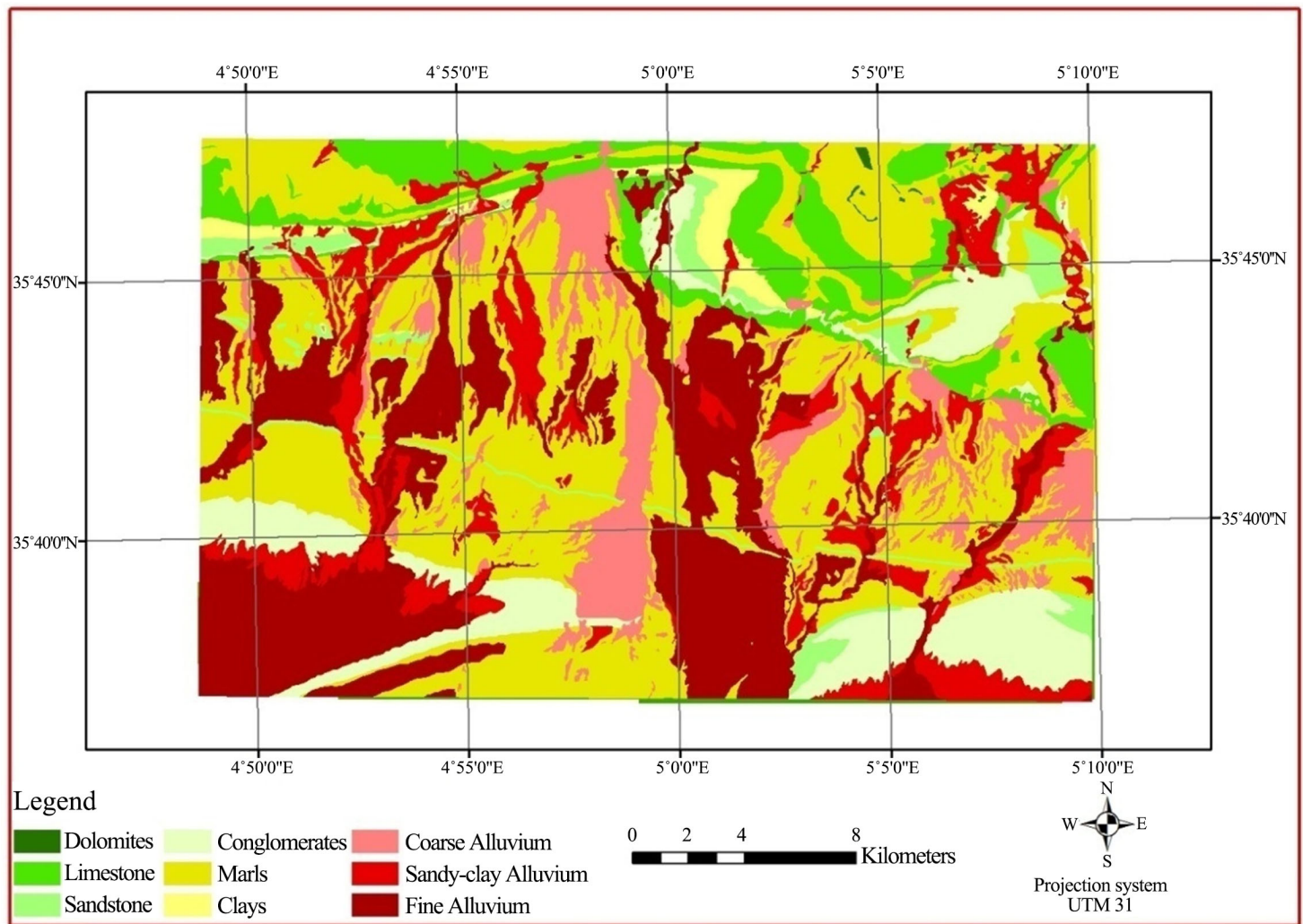

Figure 3. Lithology map of Berhoum area. 


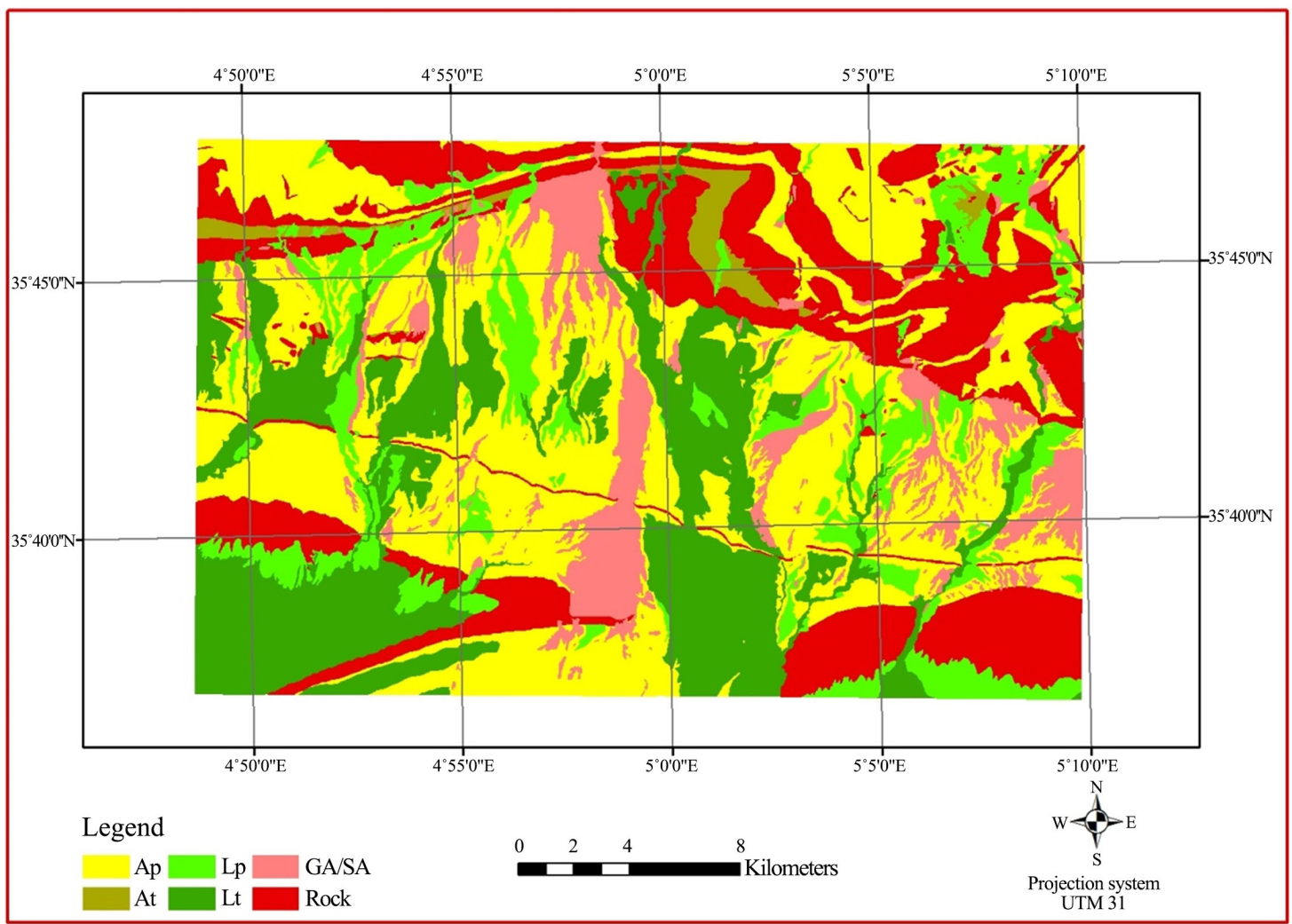

Figure 4. The soil types layer.

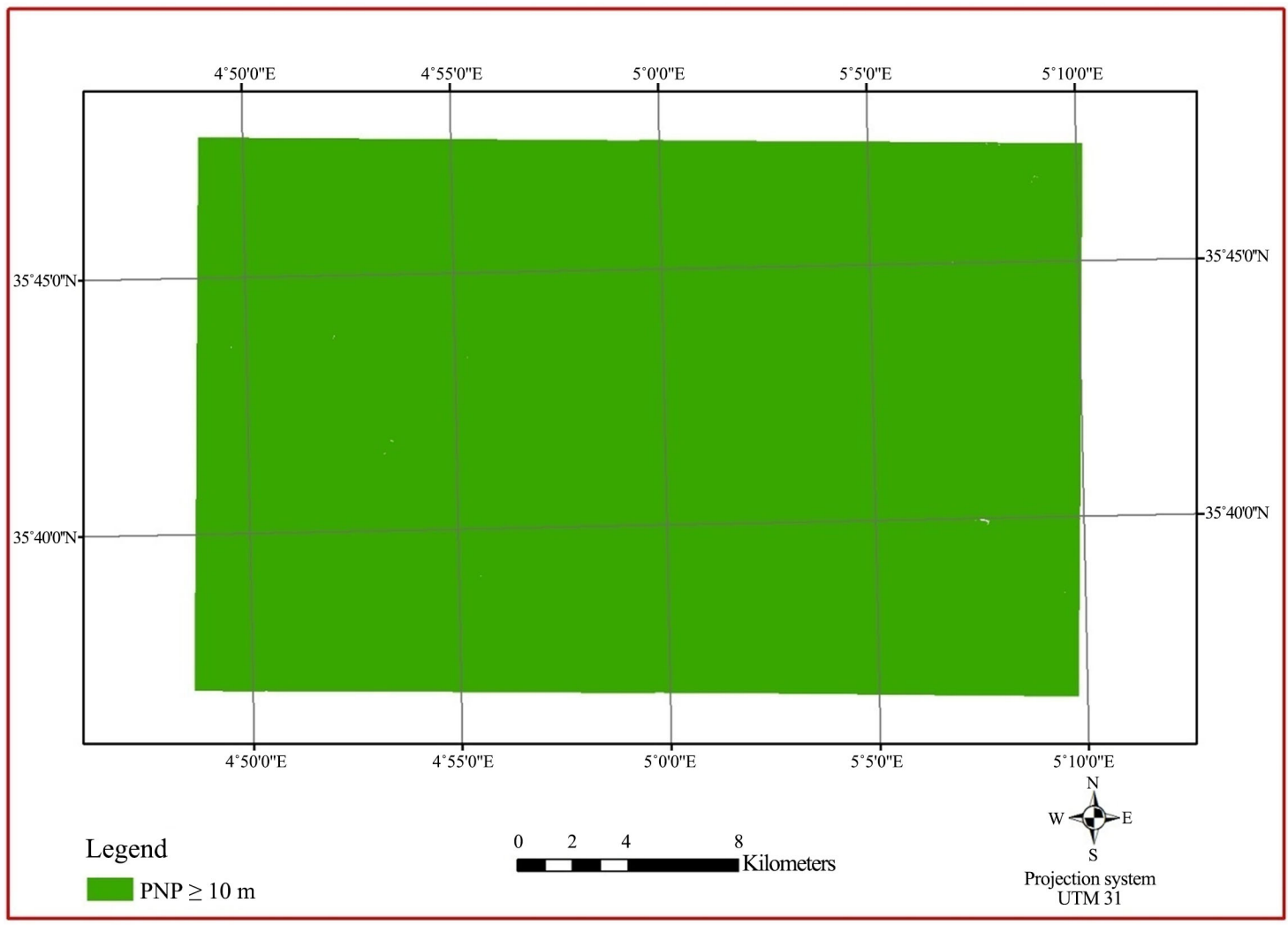

Figure 5. The ground water table layer. 


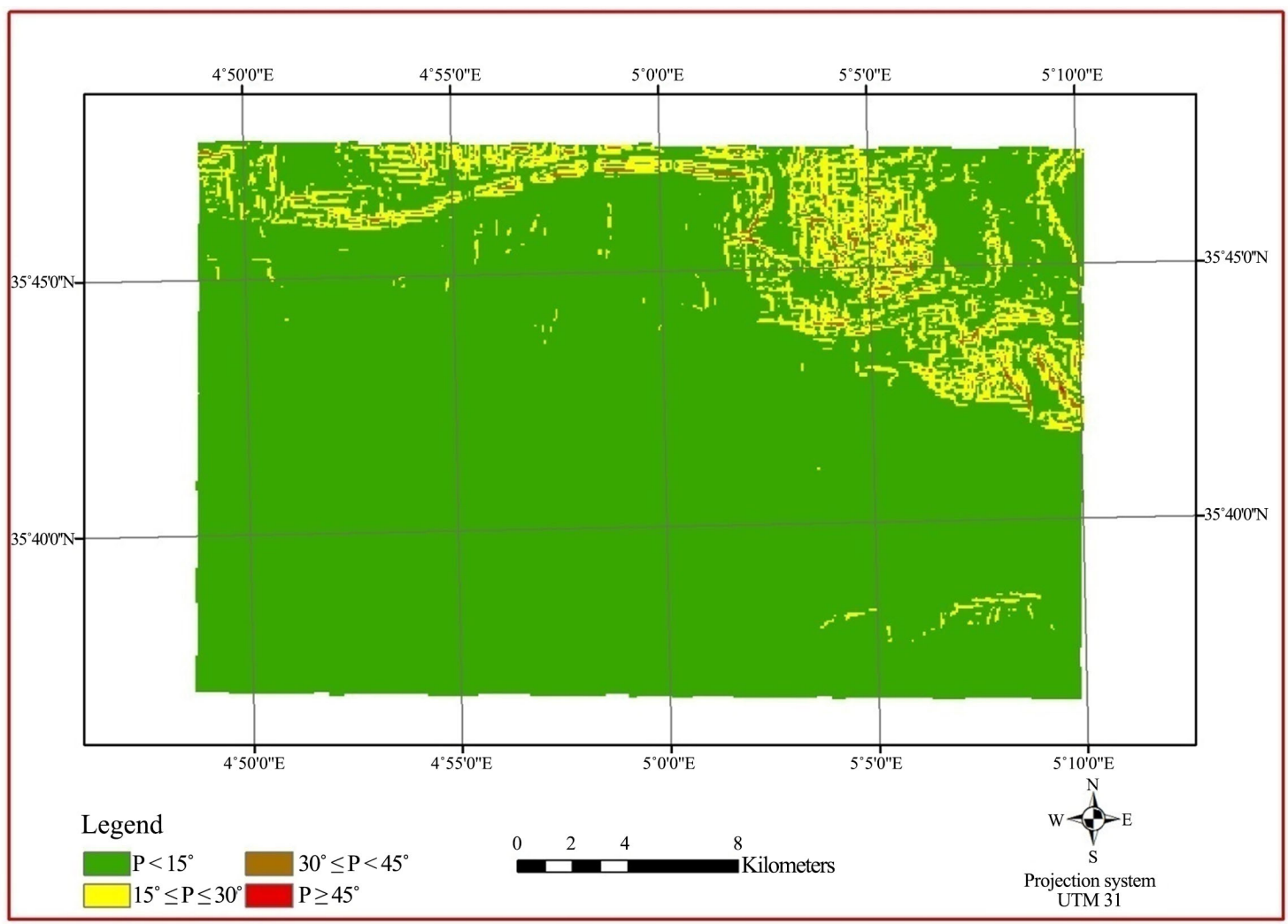

Figure 6. The slope layer.

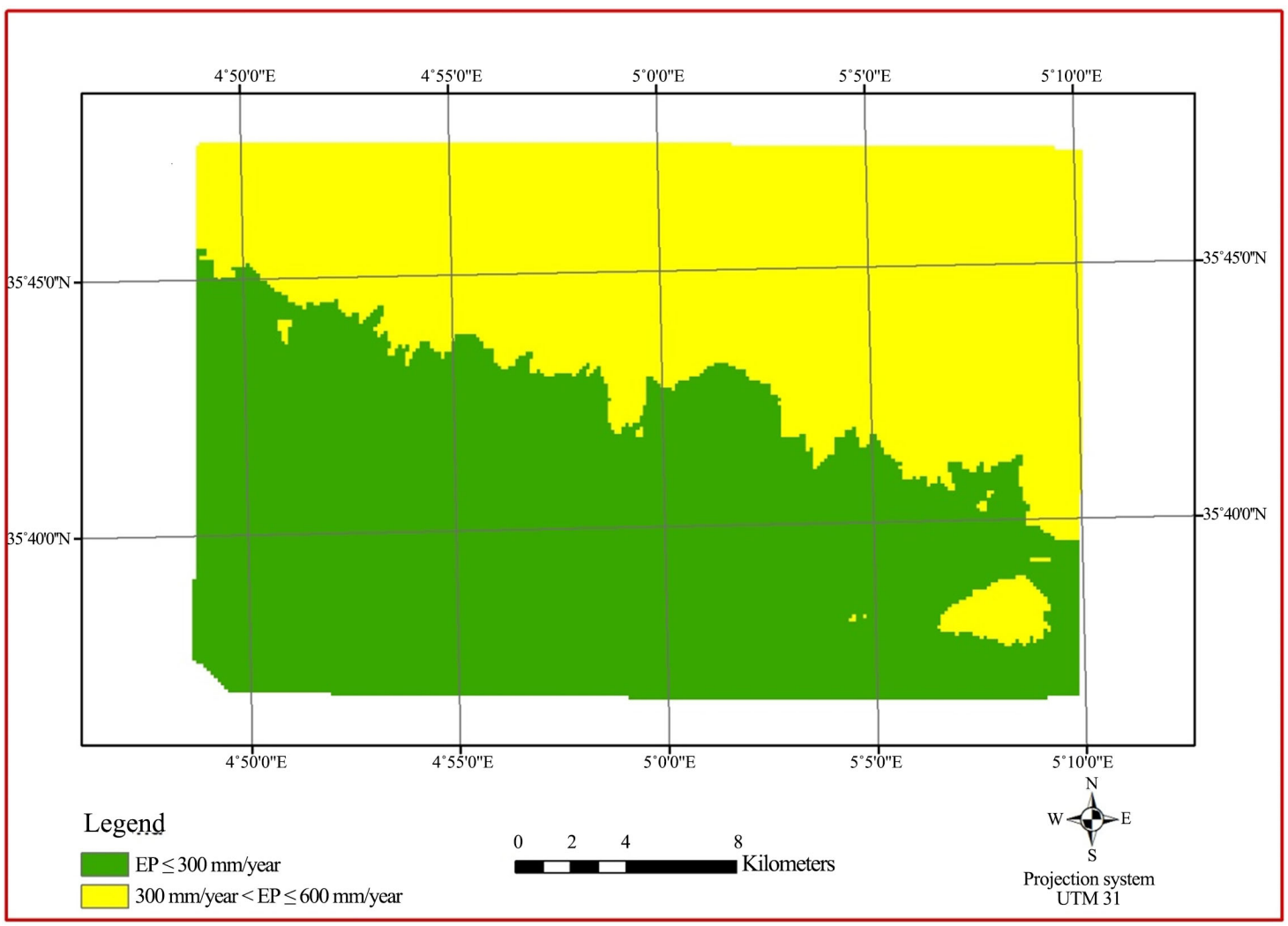

Figure 7. The rain water layer. 


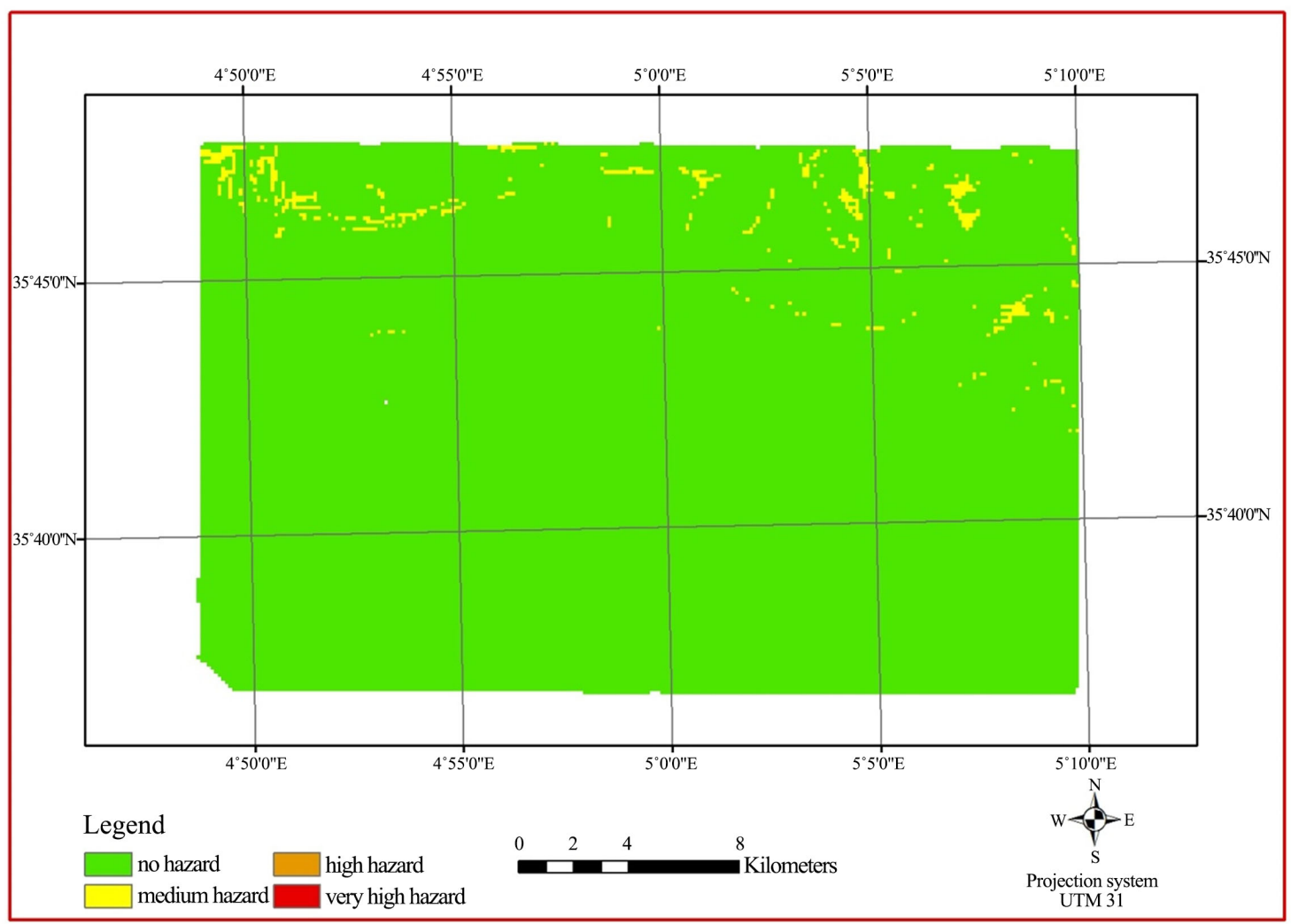

Figure 8. Landslide hazard map.

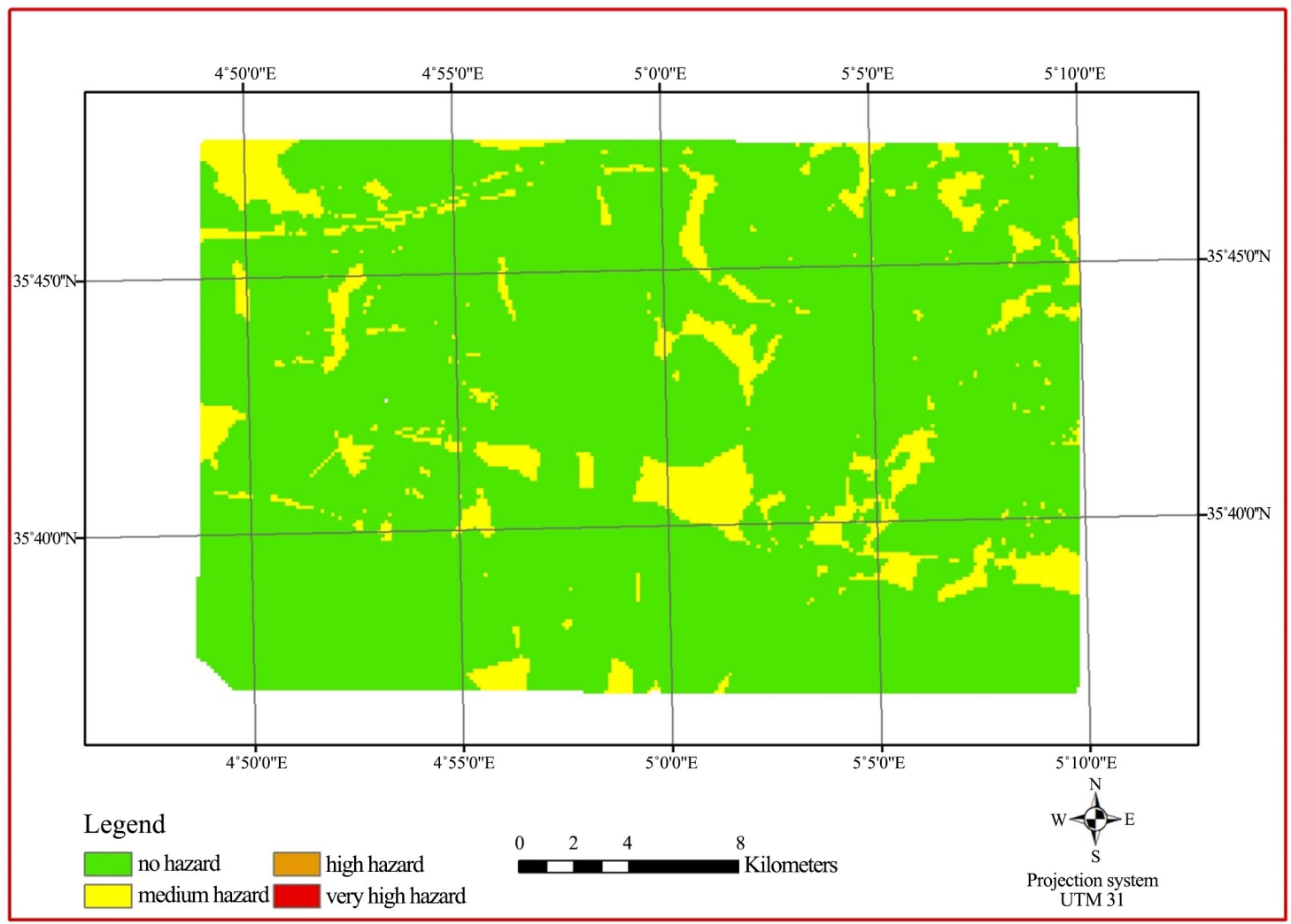

Figure 9. Shrinking-swelling soil hazard map. 


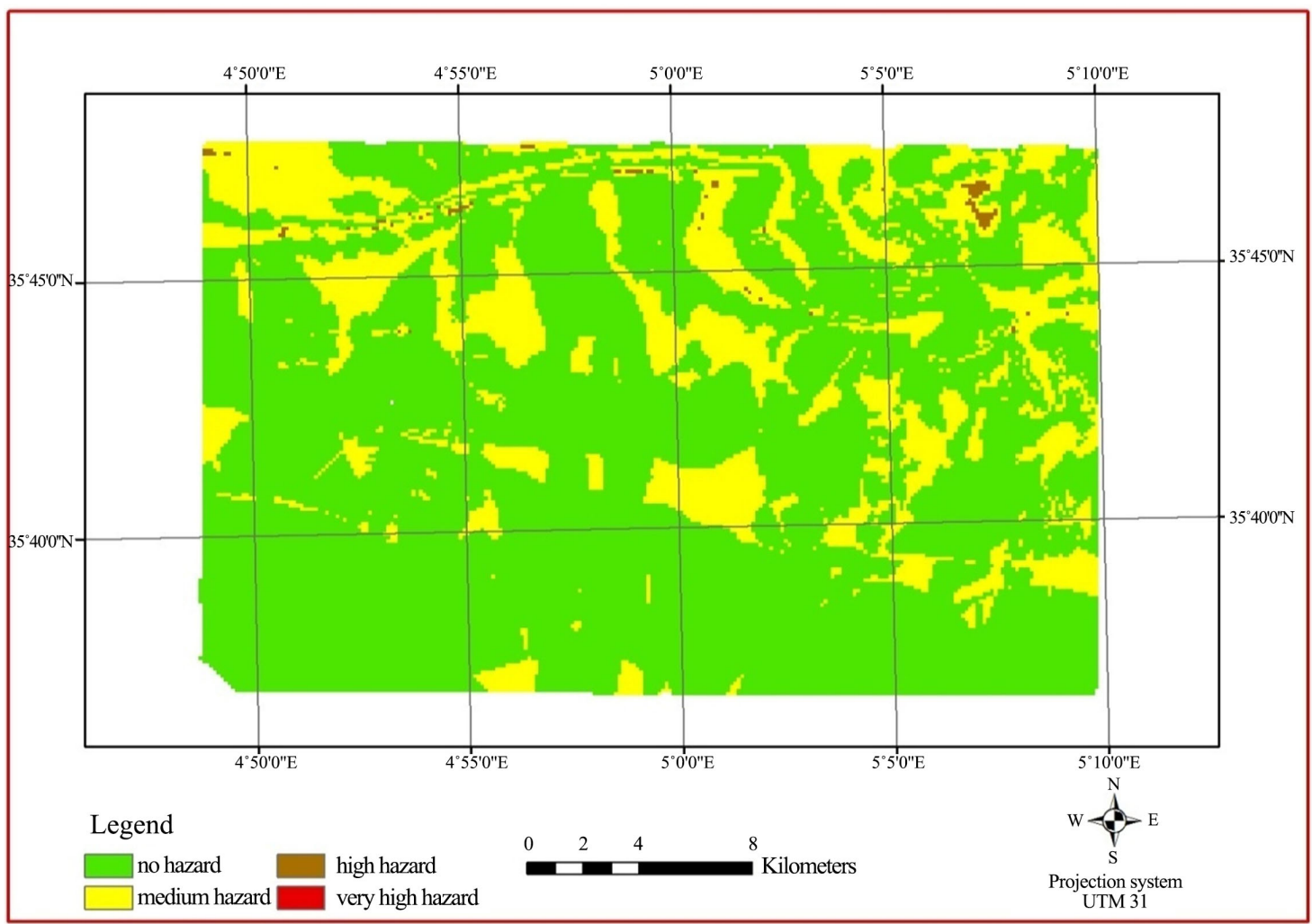

Figure 10. Land movements hazard map of Berhoum area.

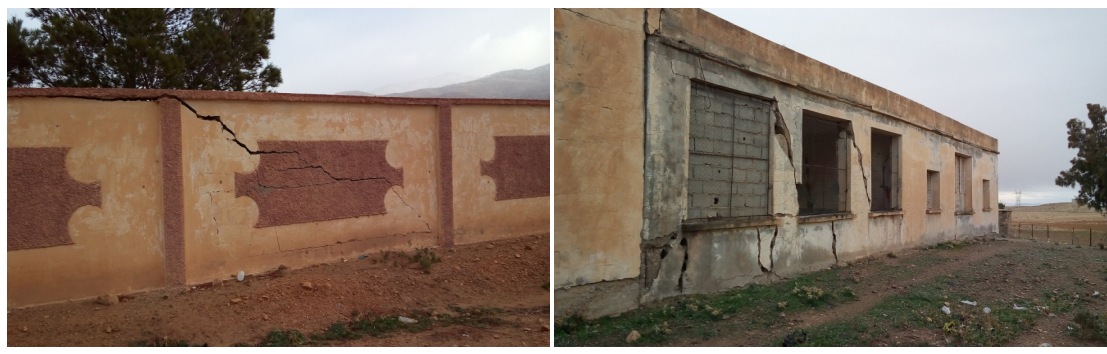

Figure 11. Field photographs showing the shrinking-swelling soil problems in the study area.

On the other hand, during field missions, the survey conducted (whether through technical offices of municipalities, by the Technical Inspection Agency of Constructions (CTC-EST, Agence de M'SILA) or directly in the field) did not record any shows slides in the study area, and therefore did not record any damage to buildings caused by landslides. Also we recorded the presence of some limited damage to buildings (Through Technical Inspection Agency of constructions reports), and are the same observations made by [25] in his research, in each of the municipalities Berhoum and Ouled Addi Gueballa, due to shrinking-swelling soil problems [26].

\section{Discussion}

The urban expansion and the increase in population led the urbanization to use 
the spaces "called at risks". The integration and the treatment of lands movements constitute an important characteristic of the equilibrium established by nature [11].

In order to solve these problems, it was necessary to propose a land movements hazard map, using the geographical information systems (GIS) with the adoption of (WSM) model. These tools enable us to express the perception of space and data processing, and consequently the cartography is carried out in an optimal way. These land movements hazard map have a great part of importance in all levels of a study as information, working paper, alert, and especially is a tool for the decision-making aid, by expressing tendencies and orientations.

The land movements hazard map of the study area (Figure 10) and a database with all the compiled geotechnical information (GEODATA) is a very important contribution to the land planning and management of the study area, and the definition of natural risk zones. It provides an excellent geotechnical data source to be consulted when new projects are being planned and designed for the study area.

An open-database, with information concerning boreholes, water table location, laboratory test data, sample locations and photographs of the samples, should be added to the Lithology, Soil types and the groundwater table maps. Such a database will permit a rapid evaluation of the conditions of the land movements hazard.

The data came from geotechnical reports provided by public institutions and also from our own fieldwork and investigations allowed the data collection to get the landslides and shrinking-swelling soil maps (Figure 8 and Figure 9). These data have been used to calculate the land movements hazard (Figure 10) by the relationship (3).

The proposed model is simple, and easily used by the geotechnical engineer or otherwise. Thread model is very interesting as it is being built on a small number of geotechnical characteristics according to experts' judgment. Similarly, this model can be easily applied to other similar regions in terms of the environmental landscape and climate. This model is not static however; it can be changed sometimes by giving a great attention to one factor and decrease it to another.

\section{Conclusions}

This work on cartography of land movements hazard, using geographic information systems (GIS) techniques, with a Weighted Somme Model (WSM), shows the interest caused by these methods, which sounds of the multiple forms, opens the way to a very sensitive improvement of the prevention of the natural risks. These tools enable us to express the perception of space and data processing, and consequently the cartography is carried out in an optimal way.

These land movements hazard maps have a great part of importance in all levels of a study as information, working paper, alert, and especially are a tool for the decision-making aid, by expressing tendencies and orientations. 
In this work, the landslides and shrinking-swelling soil maps have been prepared for Berhoum area. Weights values, analysis and classification have been assigned by Weighted Somme Model. As a result and according to the foundations efficiency, the study area has been divided into four different areas: 1) areas with no land movements hazard, 2) areas with a medium land movements hazard, 3) areas with a high land movements hazard, and 4) areas with very high land movements hazard. According to this map, low density of every kind of movements of the study area was identified.

The land movements hazard map is not a means of struggle, but it helps establish an urbanization plan and an adequate control, in addition to managing the problem of urbanization in hazardous areas, becomes possible and controllable.

The methodology used in this study for Berhoum area can be applied to other places, other procedures for the selection of the site and re-build the necessary standards appropriately.

\section{Conflicts of Interest}

The author declares no conflicts of interest regarding the publication of this paper.

\section{References}

[1] Martin, P. (2006) Ces risques que l'on dit naturels. Editions Eyrolles, Paris, 1-506.

[2] Belouar, A., Vinet, L. and Mongereau, N. (2008) Zonage cartographique des aléas glissements en milieu urbain; cas de la ville de Constantine (Algérie). Journées Nationales de Géotechnique et de Géologie de P Ingénieur, Nantes, 18-20 juin 2008, 645-652.

[3] Carver, S.J. (1991) Integrating Multicriteria Evaluation with Geographical Information Systems. International Journal of Geographical Information Systems, 5, 321-339. https://doi.org/10.1080/02693799108927858

[4] Diamond, J.T. and Wright, J.R. (1988) Design of an Integrated Spatial Information System for Multiobjective Land Use Planning. Environment and Planning B, 15, 205-214.

[5] El khattabi, J., Colbeaux, J.P., Van Lethem, F. and Boulemia, C. (2002) Identification de la typologie des mouvements de terrain du rif central (maroc) a l'aide d'une démarche méthodologique pluridisciplinaire: Résultats de l'étude préliminaire. JNGG 2002, Nancy, 8-9 Octobre 2002, 1-13.

[6] Fabre, R., Clément, B. and Lebourg, T.H. (1998) Les mouvements de terrain en Gironde (33): Cartes de risque et d'aléa. XVI ème Congrès Universitaire de Génie Civil, Reims, Vol. 2, 380-387.

[7] Guettouche, M.S. (2012) Modeling and Risk Assessment of Landslides Using Fuzzy Logic. Application on the Slopes of the Algerian Tell (Algeria). Arabian Journal of Geosciences, 1-13.

[8] Hansen, A. (1984) Landslide Hazard Analysis. In: Brunsden, D. and Prior, D.B., Eds., Slope Stability, Wiley, New York, 523-602.

[9] Martin, J.E. (1984) Réalisation d'une carte des mouvements de terrain dans les Alpes Maritimes. In: Méditerranée. Actes du colloque Effets des séismes sur les reliefs de forte énergie, Troisième série Tome 51, 93-97. 
[10] Malczewski, J. (1999) GIS and Multicriteria Decision Analysis. John Willey and Sons Inc., Hoboken, 1-392.

[11] Sidi Mohammed, A.M., Houmadi, Y. and Bellakhdar, K. (2010) Geotechnical Risks Map of Saïda City, Algeria. The Electronic Journal of Geotechnical Engineering, 15, 403-414.

[12] Kolat, Ç., Doyuran, V., Ayday, C. and Lütfi Süzen, M. (2006) Preparation of a Geotechnical Microzonation Model Using Geographical Information Systems Based on Multicriteria Decision Analysis. Journal of Engineering Geology, 87, 241-255. https://doi.org/10.1016/j.enggeo.2006.07.005

[13] Tzeng, G.H. and Huang, J.J. (2011) Multiple Attribute Decision Making: Methods and Applications. CRC Press, Boca Raton.

[14] Jato-Espino, D., Castillo-Lopez, E., Rodriguez-Hernandez, J. and Canteras-Jordana, J.C. (2014) A Review of Application of Multi-Criteria Decision Making Methods in Construction. Automation in Construction, 45, 151-162.

[15] Afshari, A., Mojahed, M. and Yusuff, R.M. (2010) Simple Additive Weighting Approach to Personnel Selection Problem. International Journal of Innovation, Management and Technology, 1, 511-515.

[16] Memariani, A., Amini, A. and Alinezhad, A. (2009) Sensitivity Analysis of Simple Additive Weighting Method (SAW): The Results of Change in the Weight of ONE Attribute on the Final Ranking of Alternatives. Journal of Industrial Engineering, 4, 13-18.

[17] MacCrimmon, K.R. (1968) Decision Making among Multiple-Attribute Alternatives: A Survey and Consolidated Approach. Advanced Research Projects Agency.

[18] Triantaphyllou, E. and Mann, S.H. (1989) An Examination of the Effectiveness of Multi-Dimensional Decision-Making Methods: A Decision-Making Paradox. Decision Support Systems, 5, 303-312. https://doi.org/10.1016/0167-9236(89)90037-7

[19] Moses, O.E. and Ada, C.G. (2016) Weighted Sum Model for Evaluating Business Environment in West Africa. Mathematical Problems in Engineering, 2016, Article ID: 3824350. https://doi.org/10.1155/2016/3824350

[20] Triantaphyllou, E. (2000) Multi-Criteria Decision Making: A Comparative Study. Kluwer Academic Publishers, Dordrecht, 1-320. https://doi.org/10.1007/978-1-4757-3157-6

[21] Guettouche, A. (2015) Cartographie géotechnique par approche SIG basée sur l'analyse multicritères-Application à la zone de Souk Ouled Nedjaa. Thèse de doctorat, FGC-USTHB, Alger, 1-144.

[22] Zardari, N.H., Ahmed, K., Shirazi, S.M. and Yusop, Z.B. (2015) Weighting Methods and Their Effects on Multi-Criteria Decision Making Model Outcomes in Water Resources Management. Springer International Publishing, Berlin. http://www.springer.com/gb/book/9783319125855 https://doi.org/10.1007/978-3-319-12586-2

[23] Guiraud, R. (1971) Notice explicative de la carte géologique au 1/50.000è de Souk Ouled Nedja. Publication du Service Géologique de l'Algérie, 35 p.

[24] Dawod, G.M. (2012) Principles of GIS Spatial Analysis. Holly Makkah, Saudi Arabia. (In Arabic) http://nwrc-egypt.academea.educ/GmaaDawood

[25] Belouar, A., Benaissa, A., Boulfoul, A. and Chikouche, F. (2008) Alea retrait-gonflement des argiles, désordres dans le bâti. Cas de m'sila (Algérie). Colloque National: 
Pathologie des Constructions. Du Diagnostic à la Réparation, Département de Génie Civil, Université Mentouri Constantine, 25-26 Novembre 2008, 1-10.

[26] CTC-EST (2016) Rapport Technique N³17/BL/SH/MS/ CTC-DR-EST-280/2016. Agence de M'SILA. Le 14/03/2016. 